\title{
ENTREVISTA COM FLÁVIO TAVARES
}

\author{
Daniela Birman ${ }^{1}$
}

O jornalista e escritor Flávio Tavares se confrontou por décadas com as extremas necessidades e dificuldade de narrar até conseguir contar o horror e a tortura sofridos por ele na ditadura militar brasileira e naquela do Uruguai. "Lutei com a necessidade de dizer e a absoluta impossibilidade de escrever. A cada dia, adiei o que iria escrever ontem", afirma ele logo na introdução do seu livro, Memórias do esquecimento, lançado em 1999.

Encarcerado três vezes pelo regime de exceção aqui instaurado, em sua última prisão no país, em 1969, Tavares foi um dos 15 presos políticos “trocados” por Charles Burke Elbrick, então embaixador dos Estados Unidos no Brasil, que havia sido sequestrado. Já no exílio, o escritor foi sequestrado e mais uma vez aprisionado. Desta vez, pelo Exército do Uruguai, quando estava de passagem por Montevidéu, em 1977.

Nesta entrevista, Tavares fala sobre o difícil processo de escrita das suas memórias de resistência e combate à ditadura brasileira. O início deste processo, ele conta, se deu após o seu retorno do exílio. Foi, pois, numa madrugada de 1980, em São Paulo, que ele escreveu o texto que se tornará depois o primeiro capítulo do livro. Neste, ele descreve o pesadelo que o perseguiu, intermitentemente, durante os seus dez anos de exílio: "Meu sexo me saía do corpo, caía-me nas mãos como um parafuso solto. E, como um parafuso de carne vermelha, eu voltava a parafusá-lo, encaixando-o entre minhas pernas (...).” Tavares não conseguirá, contudo, prosseguir com a redação. Constantemente adiado, o depoimento só será retomado com êxito quando se aproxima o aniversário de três décadas do sequestro de Charles Elbrick. "Aí é o dever que me chama e me obriga", explica, referindo-se à relevância em se aproveitar a data para colocar o tema em pauta.

E ao narrar este passado, marcado pelas torturas sofridas em 1969 e 1977 e até por simulações de fuzilamento, o jornalista teve que atravessar mais uma vez o horror e o sofrimento. "Eu me lembro de que escrevi (o livro) num ano em que houve muito frio em Búzios. E eu suava de gotejar naquelas cenas em que revivo a tortura. (...) Eu não revivi. Eu vivi”, recorda.

Ao chamar a atenção para o fato de que não reviveu a tortura, mas a viveu, Tavares, podemos supor, toca num ponto essencial da escrita do trauma: o obstáculo à simbolização do acontecimento. Pois, nesta distinção entre o revivido e o vivido estaria a lacuna deixada pelo episódio atravessado sob o impacto do terror, cuja assimilação e acesso à consciência são dificultados. Desse modo, mais do que escrever para recordar dores e histórias localizadas num outro tempo, seria necessário repeti-las, vivê-las de novo, permitindo assim que elas se transformem em memória, em narrativa. E, podemos ainda acrescentar, tornem-se de fato passado.

1 Profesora do Departamento de Teoria Literária do Instituto de Estudos da Linguagem (IEL) da Unicamp. E-mail: danielabirman@gmail.com 
Gostaria de saber um pouco mais sobre a sua decisão de escrever Memórias do esquecimento. Você contou que ela surgiu às vésperas do aniversário de 30 anos do sequestro do embaixador americano Charles Burke Elbrick. Foi isto? Ou a ideia de dar este depoimento já te perseguia?

Eu começo a escrever esse livro logo depois que volto do exílio. Eu morava em São Paulo e decidi escrever sobre a prisão de 1969. Isso era 1980. E, numa noite, comecei. E escrevi o que depois eu aproveito como primeiro capítulo. Numa madrugada. Escrevi e, depois, não fui adiante. Contei aquela história do pênis, do pesadelo (no capítulo intitulado "O exílio no sonho"). E não pude escrever mais. Fui me deitar três, quatro horas da manhã. Vinha do Estadão às oito e meia, nove da noite, mais ou menos (era, então, editorialista do jornal). E extraviei aquilo. Quando eu vejo que se aproximam os 30 anos, eu disse: tenho que escrever. Eu era muito crítico com relação ao que tinha sido escrito (sobre a ditadura). Não contra, mas crítico. E aí tento refazer aquele capítulo que eu tinha escrito. Não deu certo. Tudo que se refaz não dá certo. Tu te imitas a ti mesmo. Aí deixei, larguei. Larguei e comecei a escrever o livro, acho que ainda em Buenos Aires e, depois, vim para cá para Búzios. Aqui eu encontro o original escrito naquelas laudas de $O$ Estado de S. Paulo. Era outra coisa. Não era o boneco que eu tinha escrito, imitando a mim mesmo. Aí eu já tinha escrito quase todo o primeiro capítulo do livro (o atual capítulo dois, chamado "O sequestro”). A parte literária começa nesse capítulo dois, que é o do avião. Eu vejo uma forma de contar a mim mesmo no avião.

Logo no primeiro capítulo do livro, "O exílio no sonho", você fala sobre um pesadelo que o perseguiu durante os dez anos de exílio e que o fazia reviver, de certa forma, as torturas sofridas na prisão. Como foi ter de relembrar tudo isso?

Essa primeira parte, "O exílio no sonho", ajuda a dar o norte do livro. Em função dela é que eu entro diretamente na tortura. Eu me lembro de que escrevi (o livro) num ano em que houve muito frio em Búzios. E eu suava de gotejar naquelas cenas em que revivo a tortura. Eu suava, suava, de gotejar. Eu revivi tudo aquilo. Houve momentos, por exemplo, a descrição da minha prisão no Rio de Janeiro, em 1969... Foi uma cilada que armaram num edifício ao lado do meu, na Rua Paissandu, no Flamengo. Eu me lembro de que tive que interromper o livro. Interrompi, parei e fui me deitar. Fui me deitar e não conseguia dormir. Eu não revivi. Eu vivi. Passei a viver de novo aquele mesmo momento. Eu só não senti o gosto de metal na boca que o choque elétrico deixa. Só o que faltou foi isso. De resto, eu tive quase as mesmas reações. Então, nesse sentido, eu digo: esse livro foi o meu divã de psicanalista, a minha catarse absoluta. Realmente eu mudei. Não sei se isso é um elogio ou um antielogio. Mas eu passei a ser outra pessoa. Passei a ser mais compreensivo. A tortura e a prisão, e olha que não estou recomendando para ninguém, mas, quando se sobrevive, te dão outra dimensão. Tu vives noutra esfera. Tu sais daquela pequena esfera do cotidiano e vives outra, que te aproxima da morte. Eu tive dois momentos de aproximação da morte. Dois momentos que eu descrevo. Um quando eu chego à conclusão de que vão me atirar no rio Guandu (no Rio de Janeiro). Me botam despido só de cueca numa caminhonete e me levam: vão me atirar. 


\section{E no Uruguai...}

No Uruguai foi pior. Mas eu não ia contar do Uruguai. O livro ia terminar no Brasil.

\section{E por que mudou de ideia?}

Eu não sei exatamente por que, faz tantos anos isso. Eu acho que porque vi que esse era um livro não sobre a minha prisão, esse era um livro sobre a tortura e sobre o horror. Então eu tinha que contar do Uruguai. Só que eu atenuei muito o Uruguai. Não atenuei no sentido de não contar coisas que aconteceram. Mas eu sintetizei, sintetizei muito.

\section{Foi um período longo, né?}

Eu tinha estado preso no Brasil durante o mesmo tempo que no Uruguai. Mas foi mais longo porque eu estava preso num outro país. Eu estava preso em espanhol, não em português. Eu não tinha a quem apelar no Uruguai. A minha história no Uruguai foi a mais longa em termos dos interrogatórios que tive. Mais longa. No entanto, eu sintetizei em poucas páginas. Agora há pouco tempo, em agosto, setembro do ano passado (2011), eu estive no Uruguai, Montevidéu, para dar um depoimento sobre o desaparecimento de uma pessoa, um sujeito que foi morto ao meu lado.

\section{Isso você conta?}

Não conto. Até porque eu não tinha certeza de nada. Uma pessoa a quem eu nunca vi porque eu estava de olhos vendados. E ele possivelmente também estava de olhos vendados. Mas eu sou a única testemunha da morte dele. Porque ele esteve junto do meu lado. Eu o vi saindo mal. Depois os guardas comentavam que ele estava moribundo, mal. Eu o vi sair para a tortura, voltar da tortura, com aquela percepção que estar de olhos vendados te dá. Foi outra coisa fantástica do Uruguai: estar de olhos vendados. Eu caminhava de olhos vendados e algemado. Então eu podia caminhar. Houve um determinado momento em que, se eu baixasse assim (faz um gesto com a cabeça), eu via uma fresta. Então eu podia, por exemplo, saber que havia um risco aqui no chão, que aqui era tijolo ou não. E só isso já me dava uma alegria interior. Eu ver alguma coisa. Eu abria os olhos e via aquela frestinha. Caminhava e via a sombra, um sinal de que havia luz elétrica. Eu não tinha muita ideia se era dia ou noite.

\section{E como se sentiu, depois de tantos anos, ao finalmente ter conseguido concretizar a reda- ção deste livro?}

Eu sempre digo isso, e é verdade. Esse livro foi a minha catarse. Ele me libertou de uma série de coisas, me libertou inclusive das minhas neuroses. Depois desse livro, acho que me tornei outra pessoa. Sério mesmo. Foi o meu divã de psicanalista. Só que eu não sabia que estava fazendo uma catarse. Eu achava que não podia perder a oportunidade de lançar o livro nos 30 anos do sequestro do embaixador. O livro foi concluído ali por agosto e saiu 
em outubro de 1999. E, como eu te disse, saiu tocado meio à força porque tanto a Companhia das Letras quanto a Objetiva meio que recusaram o livro. A pessoa com quem eu tinha contato era o Luiz Schwarcz (na Companhia das Letras). Conhecia pouco, mas conhecia. E depois de uns meses ele me manda uma carta, assinada pela editora dele, elogiando o livro. Quando eu vi a carta, antes de lê-la, já sabia que era recusa, porque era uma carta muito longa. Quem aceita não faz uma carta longa. Elogiando o livro, dizendo que o livro ia marcar a história, era um grande depoimento, era um grande testemunho, mas que naquele momento não podiam publicar, não me lembro exatamente qual era o pretexto. A Objetiva tinha aceitado o livro, mas para publicar no ano seguinte, o que era também uma forma de dizer que não se está muito interessado no livro, de esfriá-lo. Aí eu percebi que havia ainda medo. Era 1999, em maio, junho. E eu percebi que havia um medo dominante no país. Medo de quê? Medo do passado. Nós temos muito medo do passado. O passado bate à porta assim como um assaltante para a nossa percepção.

\section{E foi então neste momento que você procurou a Editora Globo?}

Aí foi rapidíssimo. A editora da Globo fez um trabalho muito bonito. Ela até que sugeriu umas fotografias. Na segunda edição eu quis fazer um livro mais barato. E o caderno de fotos encarece muito. Então, em vez de fazer dois cadernos de fotos, fiz um só. Aí pedi que o Evandro Carlos de Andrade fizesse a orelha (para a primeira edição). Em seguida, inclusive, ele morreu.

Pelo que você está explicando, a escrita do livro foi a sua catarse, o seu divã. Mas você começou a escrever obrigado, achando que este era um dever seu como jornalista, um dever com a história? Você não sentia necessidade de escrever?

Tem esse aspecto: obrigado pelo dever com a história, dever comigo. Mas eu sentia muita necessidade interior. Eu me sentia em débito comigo. Cada noite eu me deitava pensando nisso: tenho que começar amanhã. E não começava. Deixava para o outro dia, para outro dia, para outro dia...

\section{Então já se sentia obrigado por essa necessidade interna e pelo dever?}

Não, no início só necessidade interior. Depois, quando eu vejo que se aproximam os 30 anos, aí é o dever que me chama e me obriga. Porque eu percebi uma coisa que é válida até hoje. Não sei se só no Brasil. Mas pelo menos no Brasil tu tens que aproveitar as datas. $\mathrm{Na}$ Copa do Mundo as pessoas falam na Copa do Mundo; no carnaval, falam do carnaval, e assim por diante. Ou seja, depois da Páscoa as pessoas nem se lembram do carnaval; no carnaval, nem se lembram do Natal. E então, disse "bom, vai fazer 30 anos, tenho que aproveitar agora." Como te disse, o livro saiu um mês depois, foi feito às pressas. E ainda estava meio fresca a história do embaixador. Mas, ainda quando saiu, saiu também com muito medo. Eu acho que esse é meu livro mais bem escrito. O êxito foi do outro, O dia em que Getúlio matou Allende. E esse aqui vale muito mais como depoimento. 
Mas ele foi premiado, né?

Ele foi premiado (com o Jabuti, categoria reportagem). O primeiro (lugar, título escolhido como Livro do Ano de Não Ficção) foi o do Drauzio Varella (Estação Carandiru), que, aliás, é um livro bem escrito. Claro, estava mais para a época.

Não teve a repercussão...

Até teve. Em termos noticiosos teve. Os jornais deram bastante. Não como depois, com O dia em que Getúlio matou Allende.

Você estava comentando que considera esse o seu livro mais bem escrito. Comparando os seus três livros, Memórias do esquecimento é o mais literário. Você acha que isso está relacionado ao assunto dele? O fato de ter que tentar contar esse horror o levou a não ficar restrito a uma linguagem jornalística?

Eu acho que sim. A pergunta é exatamente já a resposta. E acrescento outro detalhe. Quando eu percebi que tinha necessidade de fazer uma coisa dura. Eu tinha que contar da minha tortura: a tortura no pênis, a tortura na boca, a tortura nas axilas, a tortura nos olhos. Eu tinha que contar porque tinha que me libertar daquilo. Não era nem como depoimento histórico. Eu tinha que contar como a minha libertação interior. Mas eu tinha que fazer isso de uma forma que não agredisse. Eu não ia fazer o Dante nos círculos do Inferno. Eu me lembro direitinho de como escrevi o livro. Eu pensava e sentia o que escrevia. Eu tinha que pensar, raciocinar e viver aquilo que ia escrever. Eu acho que nesse aspecto é que ele se torna um livro literário. Foi vivido. É um depoimento vivido. Eu acho que a maioria dos outros depoimentos são muito secos. E eu acho que isso é que me diferencia dos demais. Eu não faço uma coisa seca.

\section{Você se refere aos outros depoimentos sobre aquele período?}

Eu acho que tem duas coisas. Uma é isso. Não há rancor nesse livro. Eu não chamo os meus torturadores de facínoras. Não há um adjetivo. É um livro objetivo. É objetivo no sentido de quê? Jornalístico? Também, mas não só por isso. Eu, sem querer, mas também querendo, fiz um livro sentido, lá do fundo. Outras pessoas diriam que fiz em estado mediúnico. Não fiz em estado mediúnico. Eu voltei a viver como se estivesse na prisão em 1969. Não sei quem me disse, há pouco tempo: “ah, me fez lembrar o Primo Levi.” Eu só fui ler o Primo Levi depois de ter escrito isso aqui. E foi muito bom que eu não tenha lido. E houve uma coisa: eu não tinha quase livros aqui em Búzios. E, por um aspecto, isso foi bom. Ou foi mau, não sei. Porque eu sempre costumo escrever intercalando com leitura. E, como eu só tinha aqui o Fernando Pessoa, mais dois ou três livrinhos de poesia, eu não tinha leitura. Se eu tivesse o Primo Levi aqui eu ia copiar o Primo Levi. Sem pretender copiá-lo. 
Você comentou que não lê muita ficção nem literatura brasileira atual. Fiquei me perguntando se Memórias do cárcere, do Graciliano Ramos, foi um livro que te marcou.

Eu li Memórias do cárcere quando foi lançado (1953). Lembro direitinho. E nunca mais. Nas epígrafes (de Memórias do esquecimento), tem uma do Graciliano. A vida inteira eu decorei isso aqui: "Liberdade completa ninguém desfruta: começamos oprimidos pela sintaxe e acabamos às voltas com a delegacia de ordem política e social." Sempre citava isso quando me perguntavam sobre liberdade de imprensa. E as pessoas ficavam maravilhadas. "Não é meu, é do Graciliano Ramos". Mas nem tenho mais aquele livro do Graciliano. E vou dizer mais. Eu não me lembro do escrito, a não ser do estilo, aquela coisa seca do Graciliano, bonita. Lembro, sim, do filme que o Nelson Pereira dos Santos fez. São três horas, e tu não queres que o filme termine.

Fiquei também me perguntando se em nenhum momento nesse livro, pelo próprio horror que você tenta contar, pela própria inverossimilhança que esses acontecimentos parecem trazer, se em nenhum momento você se sentiu tentado a resvalar para a ficção.

Não. Eu acho que todo relato, jornalístico até, sempre ficciona um pouquinho. Não no sentido de inventar, mas no sentido de tu colocares com os teus olhos. Os meus olhos são diferentes dos teus. Nós, jornalistas, descrevemos o mesmo fato de uma forma diferente. Nesse aspecto, eu acho que toda descrição, por mais realista que seja, tem algo de ficção. Mas só nesse aspecto. Eu nunca escorreguei para a ficção. O que eu faço é tentar uma interpretação e transmitir uma visão subjetiva do que eu senti. Quando eu descrevo a tortura, digo que a tortura é um aguilhão nos olhos. Não uso esse termo.

Você fala algo de cegueira.

Cegueira. Exatamente. Eu não estou ficcionando isso. Isso não é ficção. Isso é o que eu sinto hoje do que eu acho que sentia naquele momento. Nesse aspecto, pode-se dizer que não é um retrato exatamente correto, ao vivo, uma transmissão ao vivo, porque eu escrevi 30 anos depois. E eu só me senti bem, psicologicamente, depois que consegui exteriorizar, em detalhes, a história da tortura, até trazendo situações e emoções que eu acho que vivi naquele momento. Aquela história que eu te disse há pouquinho, até nem sei reproduzir, da eletricidade, do calor, da queimação que o choque produzia, o choque na narina, o choque na face, nos olhos. Até pode ser que seja uma interpretação subjetiva, pode ser que seja. Claro que naquele momento eu não dizia: “ah, tô sentindo uma queimação." Mas, quando eu vivi de novo aquilo, ou quando revivi, eu senti.

O fato de você não realizar julgamentos no livro, não dar nomes, foi uma preocupação com alguma espécie de censura? Ou você considerava isso secundário?

Isso eu acho que vem um pouco da minha formação jornalística, do meu exercício jornalístico, e um pouco da minha formação ético-cristã-católica. Os fatos não precisam de 
adjetivos. Os adjetivos são necessários quando não há fatos concretos. Os fatos são o melhor adjetivo.

\section{E aí você escapava do ideológico assim também?}

Exatamente. Eu escapava disso que se chama ideológico. Acho até que não é ideológico. Mas, fundamentalmente, eu acho que isso é uma penúria mental ou, se quiser, literária. Quando tu não tens o que dizer tu pões um adjetivo qualquer. Isso por um lado. E eu acho que isso também leva àquela história: por que vou dar nome? Até porque eu não sabia os nomes de todos eles. Por que dar nome? Isso aqui não é uma peça de juízo, não é uma peça advocatícia, não é uma peça da Comissão da Verdade, para ser atual. Não. Isso aqui é um livro, uma descrição. Os nomes pesam pouco. Eu dou o nome do almirante (Júlio) Bierrenbach, que não me torturou, e do coronel Élber de Mello Henriques, um sujeito corretíssimo. Nisso eu me cuidei. Eu não podia fazer um livro irado. Não podia fazer um livro de rancor. Até perdia o valor. Se esse livro tem algum valor, e eu hoje chego à conclusão de que tem, é porque não é um livro rancoroso, não é um livro irado, não é um livro, para usar o jargão atual, revanchista. Ele não pede a condenação de ninguém. É o testemunho de uma situação de uma época.

Entrevista concedida em abril de 2012, em Búzios 